\title{
O educador, alén de magnífico escritor, Agustín Fernández Paz
}

\author{
In memóriam
}

\section{Presentación}

012 de xullo de 2016 deixaba de estar entre nós o educador e escritor Agustín Fernández Paz. Unha figura recoñecida pola riqueza literaria dos seus textos que, maioritariamente, se dirixiron a un público lector infantil e xuvenil, pero tamén un ensinante moi destacado entre os que xeracionalmente transformaron a escola en Galicia desde a fasquía que as institucións escolares presentaban no franquismo. E mesmo un cidadán activo e presente na escena sociopolítica e cultural da Galicia das últimas décadas.

A súa é unha obra literaria profundamente situada, ao punto de que mesmo naqueles textos en que máis locen os aspectos de ficción e fantásticos non se poderían comprender sen o pano de fondo do contexto social e cultural do noso tempo. Sendo así, e estando tan presente a cuestión escolar nos seus variados textos, ao Consello de Redacción de Sarmiento. Anuario Galego de Historia da Educación pareceulle que sería acaído poñer algunha atención na súa figura. Facerlle, en definitiva, unha pequena e xusta homenaxe por medio dunha sección monográfica encadrable no que se pode entender como "historia do tempo presente", onde teñen especial vigor as testemuñas vivas.

Pensamos que a través da figura de Agustín poderiamos, ademais, percorrer una parte da historia escolar da segunda metade do século XX. El foi mestre nunha vila no espazo rural, foi ensinante renovador e creador de materiais e recursos didácticos, pertenceu a colectivos de traballo pedagóxico, foi cidadán con actuación cívica -singularmente atento ao conflito lingüístico-, incorporou nos seus textos literarios personaxes, valores, asuntos... que formaron parte tamén dos debates para a transformación cara a unha escola democrática e inclusiva. Relacionouse con outros autores e profesores do espazo hispano e de máis aló, viviu intensamente os problemas da edición educativa en contacto cos editores... de modo que estudando ou valorando xestos, accións e escritos del, ou tomándoos en consideración, poderemos estar dirixindo a ollada á nosa historia educativa aínda próxima, podendo mesmo incorporar elementos informativos de interese social.

Para isto, puidemos contar con distintas colaboracións: Isabel Soto e Xavier Senín, José Luís Polanco, Montserrat Pena, Uxía Bolaño e nós mesmos, que coordinamos esta sección. A todas e todos eles agradecemos os seus contributos. Na parte gráfica contamos 
coa colaboración de Manuel Bragado, así como con Miguelanxo Prado, o deseñador que máis acompañou ao noso autor.

Cos textos de Agustín Fernández Paz podemos achegarnos á historia da escola, comprendendo os modelos escolares alí representados, a unha reflexión crítica sobre os valores sociais en conflito, á problemática tan preocupante da normalización no ensino da lingua galega, á historia do currículo e á didáctica da lingua, á historia da lectura, á presenza da educación emocional, á conexión entre a didáctica da lectura entre nós e as posibles referencias internacionais e á memoria das loitas pola educación democrática, entre outras cuestións.

\section{Esbozo bio-bibliográfico}

Agustín Fernández Paz (Vilalba, 1947-Vigo, 2016) é un dos escritores máis coñecidos e valorados no ámbito da literatura infantil e xuvenil, en Galicia e no conxunto de España. É autor de máis de cincuenta títulos, dirixidos preferentemente a lectores infantís ou xuvenís. Os seus libros, escritos en galego, tradúcense habitualmente ás outras linguas españolas, caso do castelán, catalán, éuscaro e bable. Tamén ten diversos títulos traducidos ao portugués, coreano, búlgaro, inglés, chinés, árabe, francés e italiano.

Foi mestre e licenciado en Ciencias da Educación. Traballou como docente durante algo máis de trinta anos; como profesor de educación primaria, en particular no colexio público de Mugardos, do que tamén foi director; como coordinador de galego dos equipos de normalización lingüística dos centros de ensino, desde onde impulsou por exemplo a campaña didáctica "En galego vexo Vigo", e máis recentemente como profesor de Lingua e Literatura Galega no IES Os Rosais 2 de Vigo ata a súa xubilación en 2007.

Ademais desta dedicación á docencia, desenvolveu unha ampla actividade teórica e divulgativa, centrada en temas como a promoción da lectura, a introdución dos medios de comunicación na aula, a didáctica da lingua, a normalización da lingua galega nos ámbitos escolar e social ou no propio campo da literatura infantil e xuvenil. Foi destacado membro do movemento de renovación pedagóxica Nova Escola Galega e un dos seus fundadores, a partir da pertenza ao grupo galego de Pedagoxía Freinet. Foi, coa súa dona Inma González Reino, impulsor das Xornadas Municipais de Pedagoxía de Mugardos, de grande importancia ao longo dos anos oitenta; foi igualmente docente de cursos de formación do profesorado en lingua galega e entre 1988-90 membro do Gabinete de Estudos para a Reforma Educativa da Consellería de Educación da Xunta de Galicia.

Tamén tivo un papel relevante na elaboración de materiais didácticos de lingua e literatura como parte do Grupo Avantar (un dos textos en que participou, Canles 5, obtivo o Premio Nacional "Emilia Pardo Bazán" para libros de texto non sexistas) e participou nas series de manuais Novelos de papel (para o ensino globalizado no ciclo inicial de educación primaria),Ámote, mundo! (para a área de experiencias), Canles, Labia e O noso Galego/Lingua Galega. 
Os seus libros obtiveron numerosos premios, tanto no ámbito galego coma no español (Merlín, Lazarillo, Edebé Xuvenil, O Barco de Vapor, Protagonista Jove, Edebé Infantil, Rañolas, Raíña Lupa, Martiño Sarmiento, Xosé Neira Vilas). Foi recoñecido dúas veces como o mellor autor do ano (en 2004, pola Federación de Libreiros de Galicia e en no 2007, pola Asociación Galega de Editores). Tamén recibiu en dúas ocasións o Premio ao Mellor Libro de Literatura Infantil e Xuvenil do ano, que concede a Asociación de Escritores en Lingua Galega. A obra $O$ único que queda é o amor obtivo en 2008 o Premio Nacional de Literatura Infantil e Xuvenil que concede o Ministerio de Cultura de España (outras obras súas xa foran finalistas deste mesmo premio en anos anteriores).

No ámbito internacional salientan as catro designacións, promovidas pola Organización Española para o Libro Infantil e Xuvenil (OEPLI), ao Astrid Lindgren Memorial Award, nos anos 2008, 2009, 2010 e 2013. Novamente, O único que queda é o amor foi incluído na IBBY Honour List en 2010, como ocorrera tamén con Contos por palabras en 1992 e con Aire negro en 2002. Esta última novela, Aire negro, foi incluída no Catálogo White Ravens da International Youth Library de Múnic en 2001, un recoñecemento que tamén acadou $O$ meu nome é Skywalker en 2004.

Contos por palabras foi considerado un dos once títulos esenciais da literatura infantil española do século XX por un panel de expertos durante o Primeiro Congreso de Lingua e Literatura para Nenos e Mozos, que tivo lugar en Santiago de Chile en 2010. Un ano despois outorgóuselle en México o VII Premio Iberoamericano SM de la Literatura Infantil e Xuvenil, en recoñecemento á súa traxectoria literaria. Finalmente, a OEPLI acordou designalo como candidato español ao Premio Andersen 2012 e en xaneiro de 2013 foi investido doutor honoris causa pola Universidade de Vigo.

\section{Selección bibliográfica}

- A cidade dos desexos. 1989.

- As flores radioactivas. 1990.

- Contos por palabras. 1991. Premio Lazarillo, seleccionada pola Fundación Germán Sánchez Ruipérez como unha das cen mellores obras da literatura infantil española do século XX.

- Lonxe do mar. 1991.

- O tesouro do dragón Smaug. 1993.

- Rapazas. 1993.

- Unha lúa na fiestra. 1994.

- As tundas do corredor. 1993.

- Trece anos de Branca. 1994, Premio EDEBÉ de literatura xuvenil.

- Cartas de inverno. 1995 
- Amor dos quince anos, Marilyn. 1995.

- Avenida do Parque, 17. 1996.

- O centro do labirinto. 1997.

- A néboa escura. 1998.

- O laboratorio do doutor Nogueira. 1998.

- As fadas verdes. 2000

- Noite de voraces sombras. 2002.

- Un tren cargado de misterios. 2004.

- O meu nome é Skywalker, Premio Barco de Vapor.

- Tres pasos polo misterio. 2004.

- A escola dos piratas. 2005, Premio Edebé de Literatura Infantil e Xuvenil.

- Aire negro (Aire negre). 2001, Premi de Literatura Protagonista Jove.

- No corazón do bosque. 2007.

- Corredores de sombra. 2006.

- O único que queda é o amor. 2007, Premio Nacional de Literatura Infantil e Xuvenil.

- Lúa do Senegal. 2009.

- A dama da Luz. 2009 (álbum realizado xunto a Jorge Magutis).

- Non hai noite tan longa. 2011.

- Fantasmas de luz. 2011.

- O rastro que deixamos. 2012.

- A viaxe de Gagarin. 2012.

- A neve interminable. 2015.

\section{Sobre a condición de educador de Agustín: da aula á escrita}

$O$ indiscutible peso da figura literaria de Agustín Fernández Paz inevitablemente tende a deixar en sombra a importancia do seu labor como educador, malia terse sinalado repetidamente -foi el quen primeiro o dixo- que chegou á escrita a partir dunha esixencia nacida do seu compromiso cunha escola pedagoxicamente renovadora, para a cal non atopaba textos literarios en que se apoiar. Porque para Agustín a renovación pedagóxica nas escolas galegas tiña que estar indefectiblemente unida ao uso da lingua de noso nas aulas e daquela -inicio da década dos oitenta- os materiais publicados en galego eran 
ben escasos. Foi así como, baixo o pulo da esixencia do seu traballo docente, naceu 0 Agustín escritor.

Podería dicirse que a xénese particular da escrita literaria de Agustín Fernández Paz en certo xeito reproduciu a xénese da mesma literatura para a infancia, que naceu tamén inseparablemente vinculada, por unha parte, ao proceso histórico de escolarización e, pola outra, ao recoñecemento da condición especial do lector infantil. Mais a obra de Agustín desde o primeiro momento soubo eludir o atranco que esa dupla dependencia supuxo (e en ocasións aínda supón) para que a literatura dirixida á infancia chegase a adquirir plena condición literaria: o paternalismo didactista que somete a obrigada autonomía estética de toda auténtica creación literaria á dependencia do instrumentalismo ao servizo da transmisión de valores educativos (científicos, morais, relixiosos, políticos...), por máis que estes teñan a consideración máis alta.

Porén, a obra de Agustín é asemade un excelente exemplo de como ese perigo pode ser evitado sen por iso derivar nun ludismo desideoloxizado ou nun esteticismo amoral, como por veces semella interpretarse. Sen dúbida, o mérito literario é independente dos valores ideolóxico-morais que, explícita ou implicitamente, están presentes nun texto, mais con facilidade deste evidente aserto se ten pasado a unha conclusión que en absoluto se segue del: que nos textos literarios non debe ser visible ningún tipo de compromiso con eses valores. Ao descrédito da figura do "escritor comprometido", que no período posterior á Segunda Guerra Mundial promovera entre outros Jean-Paul Sartre, súmase no caso da literatura infantil un estreito moralismo (non poucas veces asociado a valores relixiosos) que, por certo, ten sido esgrimido para rexeitar a obra daqueles autores que hoxe consideramos parte esencial da súa historia, desde As aventuras de Tom Sawyer de Mark Twain ata boa parte das novelas para a infancia de Roald Dahl. Fernández Paz, bo coñecedor e admirador da Gramática da fantasía de Gianni Rodari, sempre foi ben consciente de que se o xogo literario de ningún xeito pode aparecer afogado pola "mensaxe" moral ou política, ao mesmo tempo nada impide que ese xogo, sen perder a súa esixencia estética, sirva de vehículo para transmitir valores.

Así, desde a súa primeira novela premiada, As flores radioactivas (Premio Xerais, 1990), o profesorado atopou na obra de Agustín Fernández Paz un aliado para promover no alumnado, sen renunciar ao gozo estético, a reflexión crítica sobre valores sociais en conflito, desde o ecoloxismo, o pacifismo, a inmigración e a xenofobia, a defensa do diferente, a marxinación social, a globalización etc. Curiosamente, en cambio, a propia escola e os valores educativos en sentido estrito non chegaron a ocupar un lugar central na obra literaria de Agustín. As excepcións son, segundo cremos, sobre todo A escola dos piratas (Rodeira 2006) e en parte Rapazas (Xerais, 1993). Nesta última, asistimos á confrontación entre unha alumna feminista e un profesor que se atreveu a dicir que "as matemáticas son coma o coñac, cousa de homes". Don Carlos non sabía ben a que se lle viña encima porque Ana non era das que calaba. Claro que, ao concluír o relato, descubrimos que os valores sexistas non son cousa exclusiva dos profesores porque, 
no curso seguinte, a amiga de Ana vai ver como a nova titora repite o estereotipo de fala masculina.

A escola dos piratas é unha fermosa alegoría a prol dunha escola activa e participativa, afastada do modelo autoritario e dirixista da escola tradicional que, por desgraza, está lonxe de ter sido erradicado. Cando unha enchente de chuvia arrastrou río abaixo a escola, o mesurado don Damián, que ata daquela nunca se atrevera a levar a contra á regulamentista e autoritaria dona Clara, a directora, transmútase no pirata Kid e, aliado coa profesora Ana Salgueiro, proclamará a "escola dos piratas" de modo que, erguendo ben alta a bandeira negra, berrou:

- Acabáronse as clases aburridas!

- Acabaron! -vocearon os nenos en coro con entusiasmo.

- Acabaron os programas que non interesan a ninguén!

- Acabaron!

- Acabaron as bibliotecas gardadas baixo chave!

- Acabaron!

- Acabáronse as visitas ao Cuarto Escuro!

- Acabaron!

- Acabáronse as ordes porque si!

- Acabaron!

- Viva a Escola dos Piratas!

- Viva! Viva!

Velaí un completo programa de innovación pedagóxica que, baixo a súa forma caricaturesca e esaxerada, enuncia un cambio respecto de inercias que a escola tradicional impón aínda por desgraza en moitas aulas: a falsa crenza de que todo valioso na educación só pode ser aburrido, a desconexión entre os obxectivos didácticos e os intereses do alumnado, a ausencia de programas de dinamización das bibliotecas e de animación á lectura, o recurso aos castigos e ao autoritarismo. Sabemos que Agustín Fernández Paz na súa práctica docente foi coherente con ese programa, como foi tamén consciente de que o seu éxito non podía ser acadado mediante a soa intervención individual. Así, en 1978 formará parte do grupo Avantar, que reúne un grupo de mestres de Ferrolterra, con algúns dos cales participará na elaboración dos primeiros manuais para o ensino do galego. Xa en 1983 será un dos fundadores do movemento de renovación pedagóxica Nova Escola Galega.

Aínda que a partir da década dos noventa o traballo literario tenderá a absorbelo cada vez máis, como evidencia tanto a cantidade como a calidade da súa obra, deixounos tamén un importante número de textos sobre a práctica educativa que sería inte- 
resante recuperar, pois na actualidade están descatalogados. Á marxe dos materiais concibidos directamente como textos escolares ou da súa participación nos deseños curriculares da Área de Lingua Galega elaborados no xa mencionado Gabinete de Estudos para a Reforma Educativa, do que formou parte entre os anos 1988 e 1990, emprestou especial atención ás dinámicas para a animación á lectura en textos como Ler en galego: Estratexias e libros para a animación á lectura dende as aulas (Ir Indo 1990) e Animación á lectura (en colaboración con Xosé Lastra Muruais e Miguel Vázquez Freire, Xerais 1991). Nesas dinámicas o labor dos intermediarios docentes, promovendo o acceso de rapaces e rapazas á lectura de obras literarias escritas na nosa lingua, ocupa un lugar esencial. Por iso, tamén dedicou textos pioneiros dirixidos a dar a coñecer esas obras cando a literatura infantil galega aínda comezaba a dar os seus primeiros pasos: Os libros infantís galegos (Xunta de Galicia 1989), 28 libros da literatura infantil e xuvenil galega (Xunta de Galicia 1989), A literatura infantil e xuvenil en galego (Xerais 1999). Pero, ademais, desde o primeiro momento tivo en conta que a lectura nas aulas non debía restrinxirse ao libro tradicional, senón que as novas modalidades de comunicación gráfica debían ser consideradas non un rival do libro, como erroneamente se chegou a ver, senón un complemento. Así, o cómic ou banda deseñada foi obxecto da súa atención en varias ocasións: Para lermos cómics (Xunta de Galicia 1989), Facermos cómics (Xerais 1991), Os cómics nas aulas (Xerais 1992).

Ao igual que coa banda deseñada, tamén consideraba que o cinema e as creacións audiovisuais non debían ser vistas como un antagonista do libro, senón que defendía a procura de sinerxías colaborativas entre os distintos medios. Antes da súa chorada morte, tivo oportunidade de ver como unha das súas novelas de maior éxito, Cartas de inverno, foi presentada en forma de novela gráfica da man do debuxante Antonio Seijas (Xerais, 2012), e manifestar a súa plena satisfacción co resultado. Seguro que lle agradaría ver esta mesma, ou algunha outra das súas obras, convertida en relato cinematográfico, e pola nosa parte coidamos que hai en moitas delas material especialmente adaptable á linguaxe das imaxes, fóra de ternos deixado algún relato (nomeadamente Fantasmas de luz, Xerais 2011, con ilustracións de Miguelanxo Prado) onde a homenaxe ao cinema e ás vellas salas cinematográficas é explícita.

Para concluírmos este breve apuntamento sobre a condición de educador de Agustín Fernández Paz, pedímoslle a unha ex-alumna súa que nos emprestase as palabras con que evoca os anos en que o tivo de mestre.

Agustín Fernández Paz foi o meu profesor durante anos no Colexio García Barbón. Cando penso en Agustín, o primeiro que lembro é o seu andar pausado, véxoo entrar na clase co seu maletín, subir á tarima e saudarnos para empezar a clase. Eu era unha nena, tería apenas 10 anos, pero facíame sentir que o que pensaba e dicía era importante e tiña valor. Era un profesor que realmente sabía escoitar e cunha paciencia infinita dedicaba a cada alumno o tempo que fose necesario ata se asegurar de que entenderas a lección. Animábanos a expresármonos, a explorarmos as nosas propias ideas, a formármonos as nosas opinións, a 
sermos creativos e a deixar voar a imaxinación. E para iso, entre outras cousas, utilizaba a literatura. Lembro que a principios de curso colgaba na parede do fondo unha lista co que no meu recordo serían centos de libros aínda que probablemente serían algúns menos. Parecíanos naquel momento algo sorprendente cando dicía que os lera todos. Non só nos convidaba a lelos, senón que nos incitaba, facía que nos picase a curiosidade sobre as historias que contaban, dándonos apenas pinceladas, de tal xeito que cando remataba de falar sempre lle preguntabamos como seguía a historia. Querías saber máis e el, riseiro, dicía que daquela non teriamos máis remedio ca lelo (Marta Rodríguez Padilla).

No seu admirable libro memorialista, O rastro que deixamos (Xerais, 2012), Agustín Fernández Paz lembra a don Félix, un mestre "tranquilo e bondadoso" que o estimulou a ler. Non hai dúbida de que Agustín foi, para os alumnos e alumnas que tiveron o privilexio de estar nas súas aulas, un mestre da mesma estirpe. A estirpe dos que merecen realmente 0 alto nome de mestre.

\section{Unha traxectoria e obra motivo de estudo}

A súa obra literaria comezou a ser motivo de estudo. 0 achegamento máis demorado foi realizado pola profesora María Eulalia Agrelo Costas, a través da súa tese de doutoramento titulada Da institución escolar ao centro do canon (baixo a dirección de Blanca-Ana Roig, Universidade de Santiago, 2015), debéndose anotar os seus frecuentes comentarios sobre unha parte das obras do autor publicados en diversos medios. Algo similar ocorre por parte da profesora Montserrat Pena Presas, quen tamén se detivo nos textos de Fernández Paz na súa tese Feminismo, xénero e coeducación na literatura infantil e xuvenil: historia crítica e aplicación didáctica (Universidade de Santiago, 2015). Cómpre salientar que estas dúas autoras, xunto con Isabel Soto López, son, probablemente, as investigadoras que máis de preto veñen abordando distintos aspectos de estudo.

Por outra banda, a súa obra foi analizada no número 108 (2014) da publicación santanderina Peonza. Revista de Literatura Infantil y Juvenil dirixida por José L. Polanco quen resalta nos textos de Agustín Fernández Paz a forza da imaxinación creativa, o constante desexo de experimentación, a riqueza de recursos narrativos e a súa calidade estética. Para tal fin, obsérvase a presenza de variados procedementos literarios, o uso de elementos fantásticos que alteran a realidade, o xogo coas palabras e coa estrutura dos seus textos, a mestura de realidade e ficción, a diversidade de xéneros, así como a constante referencia a outras obras literarias e cinematográficas. Ademais, saliéntase aquí a riqueza temática en que aparecen como tópicos constantes a preocupación pola dignidade humana, a cuestión ambiental e a diversidade, a inmigración, o paro, a muller e en particular as nenas, a aceptación das diferenzas humanas en canto que diversidade, a loita pola xustiza, a soidade, e a necesidade de recuperar a memoria do pasado en contra do esquecemento ligado á cuestión da II República e a represión posterior franquista. 
Un monográfico no que colaboraron Xabier P. DoCampo, Xavier Senín, Isabel Soto, M. a Jesús Fernández, Martín Pawley e o propio Agustín Fernández, ademais do ilustrador e creador Miguelanxo Prado. Referimos nomes de escritoras ou de profesores que, como o de Xosé Lastra Muruais, ou o do editor Manuel Bragado Rodríguez, ou a da escritora Ledicia Costas, tiveron igualmente unha forte conexión vital, que aquí anotamos.

Quede, entón, unha imprescindible constancia. A súa obra será, sen dubida, motivo de atención, de afondamento e de investigación.

Antón COSTA RICO Miguel VÁZQUEZ FREIRE

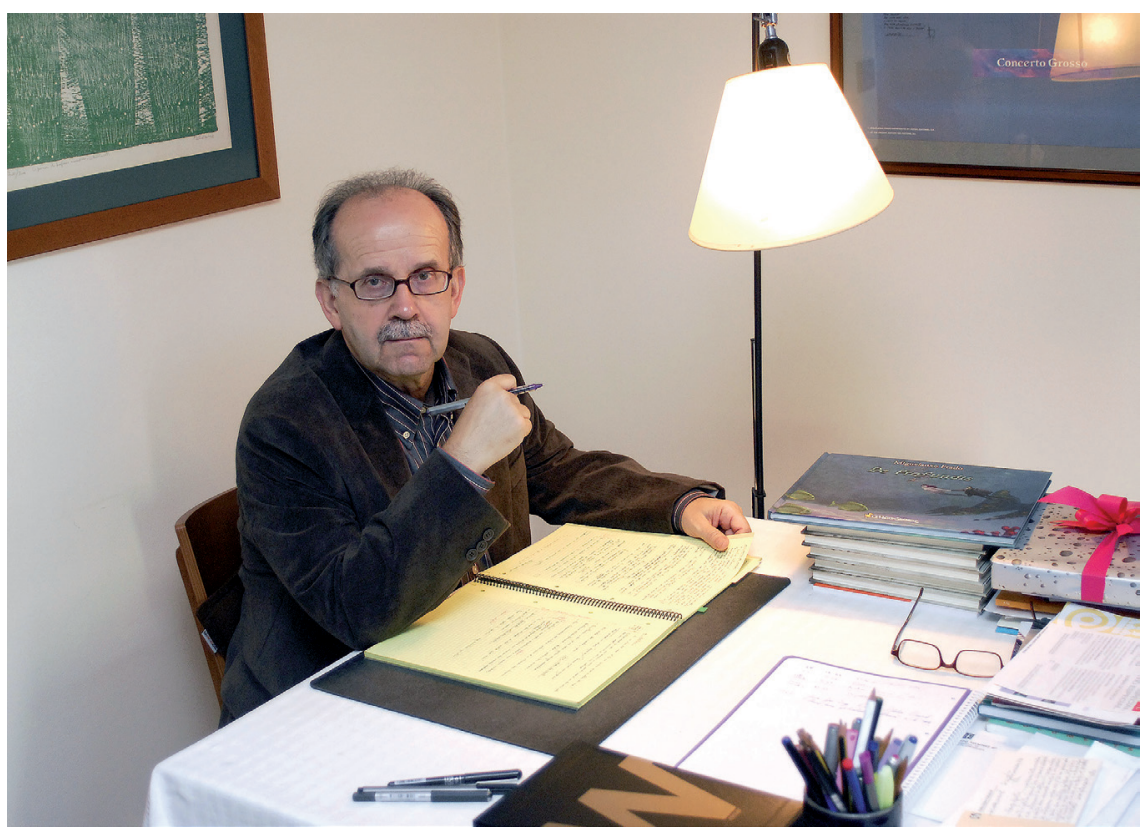

